\title{
O FUNCIONAMENTO COGNITIVO DE IDOSOS E DE ADOLESCENTES NUM CONTEXTO DE JOGO DE REGRAS
}

\author{
Claudimara Chisté Santos* \\ Claudia Broetto Rossetti** \\ Antonio Carlos Ortega ${ }^{* * *}$
}

\section{Resumo}

Os estudos sobre a cognição, em muitos casos, se referem principalmente à memória e atenção. Nesta pesquisa, utilizamos o modelo proposto por Piaget (1977), denominado Tomada de Consciência. Este recorte da teoria visa analisar aspectos relacionados ao processo do funcionamento cognitivo do idoso. $\mathrm{O}$ objetivo da pesquisa foi caracterizar o processo de Tomada de Consciência de idosos e adolescentes, num contexto de jogos de regras. Os participantes residiam em bairros de classe média e tiveram sua formação em escolas públicas. Os adolescentes cursavam o primeiro ano do ensino médio e os idosos já o haviam concluído. A escolha por adolescentes se deve ao fato de que para Piaget, o ápice do desenvolvimento cognitivo é o estágio lógico-formal, atingido a partir da adolescência. Entretanto, o objeto desta pesquisa foi o funcionamento cognitivo do idoso. O adolescente foi incluído para auxiliar a definição das características encontradas, de modo a proporcionar melhor entendimento sobre o processo no envelhecimento, em situações minimamente controladas. Trata-se de um estudo exploratório, de natureza qualitativa, baseado no método clínico de Piaget. Esta pesquisa foi realizada com dois adolescentes e dois idosos jovens. O instrumento utilizado para coleta de dados foi um jogo de regras chamado Quoridor. Os resultados indicam que, em muitos aspectos, o processo de Tomada de Consciência dos idosos e adolescentes pesquisados se assemelhou. Contudo, diferenças qualitativas foram

\footnotetext{
* Professora do Curso de Psicologia da UNIVIX - Faculdade Brasileira e mestranda do Programa de Pós-Graduação em Psicologia da Universidade Federal do Espírito Santo - UFES. E-mail: claudimarachiste@uol.com.br

** Professora do Departamento de Psicologia e do Programa de Pós-Graduação em Psicologia da UFES. Doutora em Psicologia pela Universidade de São Paulo - USP. E-mail: cbroetto@npd.ufes.br

*** Professor do Programa de Pós-Graduação em Psicologia da UFES e do Curso de Psicologia da Unilinhares. Doutor em Psicologia pela Fundação Getúlio Vargas, Rio de Janeiro. E-mail: acortega@terra.com.br
} 
observadas em toda a análise dos dados, e podem indicar direção para o desenvolvimento de intervenção nos aspectos cognitivos de idosos.

Palavras-chave: Envelhecimento. Piaget. Jogos. Tomada de Consciência. Cognição.

\section{Idoso e a Cognição}

O envelhecimento é um tema que cada vez mais tem sido considerado relevante na área do desenvolvimento humano. $\mathrm{O}$ aumento da expectativa de vida gera um acréscimo gradual no interesse por esse tema. Segundo o Instituto Brasileiro de Geografia e Estatítica (IBGE, [200-?]), em 2050, a expectativa de vida nos países em desenvolvimento será de 82 anos para homens e 86 para mulheres. Para se ter uma idéia deste aumento, no início do século XX o ser humano podia esperar viver em média 33,7 anos. No final desse mesmo século, já se podia ter esperança de vida de uma média de 68,5 anos (BRASIL, 2001, p. 8-9). As pesquisas precisam acompanhar esta nova realidade, desenvolvendo tecnologias que possam amparar políticas públicas de prevenção nas áreas de saúde e educação, baseadas nessas transformações.

Para efeito de sistematização nesta pesquisa, trabalhamos apenas com idosos jovens, ou seja, na faixa de 65 a 75 anos (BEE, 1997). Ainda há muitas controvérsias sobre a conceituação de idoso, mas é possível apontar tendências no estudo da velhice na atualidade. Neri (2001) faz uma análise em que descreve três visões sobre a velhice, baseadas em premissas que vão de um pessimismo completo a um otimismo exagerado. A primeira se baseia nas idéias organicistas de um determinismo biológico. Envelhecer, neste caso, corresponde a um movimento inevitável de um declínio para um estado já programado. O tempo e a biologia fazem o seu papel. Uma segunda premissa corresponde ao que a autora descreve como uma "aura de charlatanismo", que de certa forma procura negar o inevitável declínio físico decorrente do envelhecimento. Há ainda uma terceira vertente, que admite as limitações físicas causadas pelo tempo, mas que também vê o desenvolvimento humano como sendo determinado por uma variedade de fatores, tais como: tipo de relações familiares e interpessoais mantidas pelo indivíduo, prática de exercícios físicos e atividades intelectuais. Esta vertente considera a possibilidade de alguns ganhos ao longo do tempo. 
Esta última visão é a adotada neste artigo, compartilhada tanto pelos dados empíricos encontrados ao longo da coleta de dados, quanto pela revisão de literatura acerca do tema. Trata-se aqui do tipo de olhar que é lançado sobre a situação de envelhecer. Pode-se considerar os declínios, claro. Sempre há. Mas pode-se considerar também o estado atual e, principalmente, o processo do pensamento de cada indivíduo, de forma a atuar sobre a construção do conhecimento nesta fase da vida.

Quando se trata de retratar um idoso, é preciso considerar variações individuais muito grandes. Por exemplo: há indivíduos com 65 anos sofrendo de doenças crônicas, com pouca autonomia, enquanto há outros com 80 anos com ativa participação social e boa imagem de si próprio. Alguns dados entram em desacordo com a visão de um idoso incapaz e, necessariamente decadente. O processo de envelhecimento não se dá de maneira uniforme para todos os indivíduos (ANSTEY; HOFER; LUSZCZ, 2003; ARGIMON; STEIN, 2005; DENISE et al., 2002; DÍAZ.; MARTINEZ LOZANO; NUNEZ RODRIGUEZ, 2003; LÖVDÉN; GHISLETTA; LINDERBERGER, 2005; SCHAIE, 2004, 2005; STEVENS et al., 1999; WEST; BAGMWELL; DARK-FREUDEMAN, 2005). Estes estudos indicam que atividades diversas podem atenuar o declínio cognitivo dos idosos. Baseados nesta premissa podemos supor que um idoso que faça exercícios físicos, realize trabalhos voluntários, tenha a função de cuidar dos netos, mantenha uma atividade remunerada ou participe assiduamente de um grupo de amigos, tenderá a ter menor declínio cognitivo.

Considerar que fatores ambientais têm influência significativa no declínio cognitivo, implica, necessariamente, em aceitar a posição de que não há um tempo pré-determinado e fixado para o indivíduo diminuir suas habilidades cognitivas. Na revisão de literatura não foram encontrados estudos com dados conclusivos sobre as condições em que as habilidades cognitivas começam a declinar, principalmente porque estudos transversais, que comparam grupos de idades diferentes, numa mesma época, têm dificuldade em controlar todas as variáveis determinantes de variações cognitivas (BEE, 1997; PAPALIA; OLDS, 2000). Os métodos científicos são produto de uma época, de um pensamento filosófico e de crenças pessoais. Por esta razão foi preciso deixar clara a visão de idoso adotada neste estudo.

O Estudo Longitudinal de Seatle (SCHAIE, 1996) trouxe contribuições para esta questão do declínio cognitivo. Utilizando métodos longitudinais e transversais, o autor pesquisou indivíduos entre os anos de 
1956 a 1991. A cada sete anos eram introduzidos novos participantes na amostra. Um de seus objetivos era avaliar se havia declínio cognitivo em idosos. Ele concluiu que a partir dos 70 anos, em média, se começa a ter um pequeno declínio de algumas habilidades, mas outras, que ele chamou de "inteligência cristalizada", tendem a se conservar na velhice, desde que não haja problemas de saúde significativos. A importância dos estudos de Schaie se deve ao trabalho com métodos transversais e longitudinais, o que garante um controle maior de variáveis.

A revisão da literatura foi realizada utilizando três bases de dados: Ovid, PsycInfo e Scielo. Os critérios de inclusão para a escolha dos artigos foram: envelhecimento ou expressões similares (terceira idade, idoso, envelhecer/ elderly, old aging, adulthood) e cognição (funcionamento cognitivo, memória, inteligência, desenvolvimento, aprendizagem, cognitive function, sensory function, cognitive skill, intellectual development, memory).

Os critérios de exclusão diziam respeito aos processos cognitivos relacionados a outras etapas de desenvolvimento: infância e adolescência. Também foram excluídos estudos que tratavam exclusivamente dos aspectos fisiológicos e medicamentosos relacionados à memória e inteligência. A fase adulta não foi usada como critério de exclusão.

Tal revisão indica, portanto, alguns pontos de partida:

a) o número de idosos aumenta nos países desenvolvidos e em desenvolvimento;

b) fatores físicos (hereditários e condições de saúde) e ambientais são determinantes para o declínio da cognição;

c) alguns aspectos da inteligência podem permanecer intactos ao longo de toda a vida, desde que mantidas condições de saúde.

A questão nesta pesquisa não foi estabelecer o quanto os idosos pesquisados eram mais lentos ou sábios que os adolescentes. Não se trata de uma questão dicotômica velhice - juventude. Trata-se do processo de Tomada de Consciência tal como proposto por Piaget, que se caracteriza por manter, numa fase da existência, elementos transformados de fases anteriores. Esta característica é fundamental para se pensar o processo de desenvolvimento cognitivo no idoso. É neste contexto que se insere a questão da pesquisa: como se processa o pensamento num idoso? Por se tratar de uma questão tão ampla, é que recorremos ao modelo da Tomada de Consciência. 
2 O Processo de Tomada de Consciência: um modelo piagetiano

Piaget $(1977,1978)$ relata inúmeros experimentos, todos destinados a descrever como se dá o processo de Tomada de Consciência. Ao final de cada experimento, ele esclarece um aspecto, delineia um ponto a mais sobre este conceito. Nesses experimentos, utilizando o método clínico, ele solicita aos sujeitos que façam uma determinada tarefa e faz perguntas, com o objetivo de que relatem os meios utilizados para obter êxito, ou os motivos que levaram ao fracasso em algumas situações. Assim, Piaget tem acesso aos graus de conceituação que eles fazem sobre sua própria ação. Há casos em que crianças pequenas obtém êxito, mas não conseguem explicar o porquê. Ele identificou que quanto mais velhas as crianças, maior a chance de elas descreverem os motivos, meios e intenções para alcançarem êxito. O processo de Tomada de Consciência acontece, segundo Piaget (1977) da periferia para o centro, ou seja, ele começa na periferia (tanto do objeto quanto do sujeito) para o centro. Percorrer o caminho para a centralidade implica num maior conhecimento tanto do objeto como do próprio sujeito.

Por que é importante conhecer a conceituação sobre a ação de um indivíduo? Esta pode ser uma boa oportunidade para intervir em situações de aprendizagem e/ou disfunções. É valorizar o erro e o acerto em seu processo, e não apenas como resultado de uma ação. De acordo com Macedo (1994, p. 164), “[ . . . ] a tomada de consciência é sempre de uma ação, e isso é o que importa frisar." Estudar o processo de Tomada de Consciência pode fornecer indícios para entender os processos inferenciais, presentes na relação sujeito - objeto, que muitas vezes não estão conscientes. A partir do momento que o sujeito entende como obteve êxito, ou o que o levou ao fracasso, ele pode fazer novas regulações (PIAGET, 1976) e modificar sua compreensão de si mesmo e do objeto. O conceito de regulação precisa ser entendido para completar a compreensão do processo de Tomada de Consciência.

Imagine um indivíduo, em qualquer faixa etária, diante de um quebracabeça. Ele pode ou não obter êxito. Independente do resultado, a interrelação dele com o objeto poderá provocar desequilíbrio em suas estruturas mentais, que são compostas por esquemas. A regulação acontece no momento em que o sujeito equilibra estas estruturas mentais, acrescentando algo aos esquemas ou modificando-os. Segundo Moro (2005), a Tomada de Consciência é uma das dimensões que pode transformar esses esquemas em um conceito. Voltando ao exemplo do quebra-cabeça, conceituar a ação 
poderia ser representado pelo fato de conseguir explicar as estratégias utilizadas, os conceitos empregados e até extrair fórmulas matemáticas que expliquem a ação. Para Moreno Hernández (1998), o processo de Tomada de Consciência torna possível níveis cada vez mais complexos de regulações e conceituação sobre a ação. Tomar consciência não significa apenas perceber um conhecimento que já estava pronto, mas que apenas não era considerado. O processo de Tomada de Consciência, por si só, é responsável pela evolução do pensamento. Ele se constitui numa conduta capaz de gerar novas equilibrações. Nestas condições, o método qualitativo se apresenta como mais adequado para a investigação deste processo, na medida em que permite uma análise pormenorizada das intenções do indivíduo durante e depois de sua ação.

\section{O Jogo no Contexto da Pesquisa}

Piaget, em seus experimentos, costumava utilizar vários materiais, desde os mais simples a alguns mais elaborados. Ao longo de sua obra, não deixou escapar a importância dos jogos na construção do conhecimento. Ortega et al. (2000) faz uma revisão dos trabalhos de Piaget sobre jogos, e menciona três livros: O Juízo Moral na Criança, A Formação do Símbolo na Criança e As Formas Elementares da Dialética. No primeiro livro Piaget se dedicou a analisar o desenvolvimento moral das crianças de acordo com o comportamento que apresentavam diante das regras do jogo; no segundo livro procurou identificar as estruturas dos jogos de acordo com as fases do desenvolvimento; no terceiro, já no fim de sua vida, ele priorizou o estudo da formação do pensamento dialético. Em estudos mais recentes, tornou-se uma prática utilizar jogos de regras nos procedimentos de pesquisa ou mesmo colocá-los eles próprios como objeto de estudo. Rossetti e Souza (2005) em uma pesquisa sobre preferência lúdica, fazem uma revisão de vários trabalhos relacionando investigação científica com jogos. Segundo os autores, foi possível encontrar três grupos de trabalho associando jogos de regra à investigação científica:

a) o grupo organizado pelo Prof. Lino de Macedo, no Instituto de Psicologia da Universidade de São Paulo;

b) os trabalhos da Prof. Rosely Palermo Brenelli, na Faculdade de Educação da Universidade Estadual de Campinas; 
c) o grupo desenvolvido pelo Prof. Antonio Carlos Ortega, da Universidade Federal do Espírito Santo.

Na revisão bibliográfica realizada, não foram encontrados estudos que envolvessem idosos e jogos de regras.

O jogo tem inúmeras vantagens como instrumento de pesquisa. Sob a ótica do participante da pesquisa, nem sempre é confortável a posição de ser observado, analisado e, em última instância, avaliado. Ojogo, obviamente, é uma ferramenta e, desde que bem utilizado, tem a tendência de ser um objeto intermediário entre o pesquisador e o participante, ou até mesmo entre os próprios participantes. O divertimento cria o clima de baixa tensão, e a competitividade cria o ambiente motivador, ambas condições necessárias a uma coleta de dados adequada.

Durante um jogo é possível detectar informações sobre como o jogador pensa e como soluciona problemas ocasionais (MACEDO; PETTY; PASSOS, 2000). O pensamento não é acessível ao pesquisador, mas a ação e a linguagem possibilitam acesso ao funcionamento cognitivo e, mais precisamente, ao processo de Tomada de Consciência.

\section{Método}

Esta investigação exploratória é justificada pela escassez de produções científicas com os recortes aqui utilizados, ou seja, uma investigação acerca da Tomada de Consciência de idosos jovens por meio do jogo Quoridor. O método clínico de Piaget foi utilizado tanto para a coleta quanto para a análise de dados (PIAGET, [19-], p. 5-27).

Em relação ao delineamento de pesquisa, o problema levantado, que diz respeito à caracterização o processo de Tomada de Consciência de idosos e adolescentes, refere-se a uma questão descritivo-comparativa. Segundo Meltzoff (2001), questões deste tipo são utilizadas quando se pretende comparar dois ou mais grupos pré-existentes, como é o caso, focando uma única variável, que é a faixa etária. Apesar da dificuldade em controlar as variáveis intervenientes, faz-se necessário a utilização de grupos pré-existentes, devido ao tipo de problema formulado. Os participantes da pesquisa foi uma dupla de idosos e outra de adolescentes, todos do sexo masculino. Os adolescentes eram alunos do $1^{\circ}$ ano de ensino médio, de uma escola pública de Vitória, um com 17 e outro com 18 anos. Ambos dependiam financeiramente dos pais. Um dos idosos tinha 65 anos e era responsável por um grupo 
folclórico. O outro tinha 67, e era vendedor autônomo. Nenhum dos participantes alegava problemas crônicos de saúde. A escolaridade dos quatro participantes ficou entre a $7^{\mathrm{a}}$ série do ensino fundamental até o $1^{\circ}$ ano do ensino médio.

\subsection{Instrumentos}

Como instrumento de investigação foi utilizado o jogo Quoridor, na versão para dois participantes. Ao contrário de muitos jogos utilizados em pesquisas, o Quoridor não é um jogo antigo. Foi inventado por um italiano chamado Mirko Marquesi, com o nome de Pinko Pallino (IL FOGLIACCIO DEGLI ASTRATTI, 2004). Em 1997, a Gigamic comprou os direitos e reeditou o jogo com o nome que é utilizado até hoje. No Brasil, ele ainda recebe o nome de Barreiras ou Curral, devido aos desafios que podem ser colocados durante uma partida.

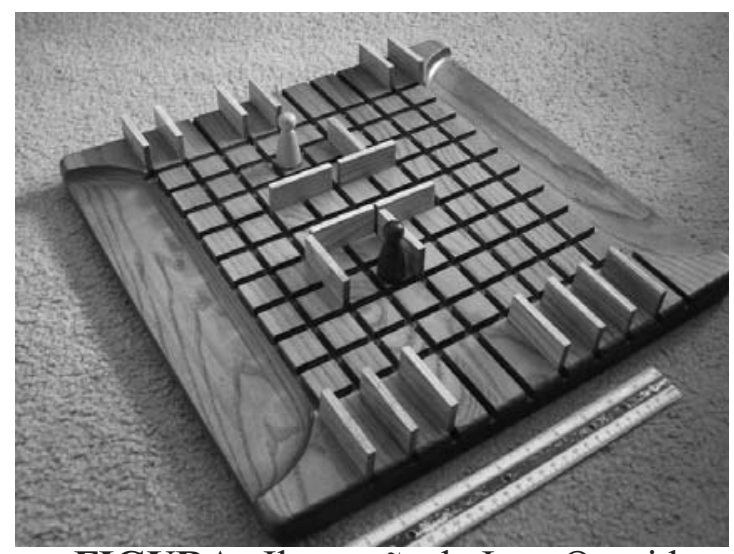

FIGURA-Ilustração do Jogo Quoridor Fonte: PIC88865.JPG (2005).

O jogo é formado por tabuleiro em madeira, com quatro peões e 22 barreiras. Ganha o participante que atingir em primeiro lugar qualquer casa na linha oposta a sua linha de partida. No início as barreiras estão colocadas atrás da linha de partida de cada jogador, sendo dez barreiras para cada jogador (duas pessoas), sete barreiras para cada jogador (três pessoas), ou cinco barreiras para cada jogador (quatro pessoas). Cada um dos jogadores escolhe deslocar o seu peão ou colocar uma das barreiras. Os peões deslocam-se de uma em uma casa horizontal ou verticalmente, para frente ou 
para trás e para os lados, mas nunca na diagonal. As barreiras devem ser contornadas, não se pode pular sobre uma barreira. A barreira deve ser colocada exatamente entre duas casas. A colocação das barreiras não pode fechar totalmente o acesso à linha de chegada do adversário. Quando dois peões se encontram face a face em casas vizinhas não separadas por barreiras, o jogador pode saltar o peão do adversário. Não se podem pular dois peões de uma vez, no caso de estarem jogando três ou quatro pessoas. Nesta pesquisa, foi utilizado o jogo na versão para dois participantes.

\subsection{Procedimento}

Foram elaborados protocolos de registro de cada jogada. As partidas foram gravadas por áudio e vídeo, com a participação de dois auxiliares de pesquisa ${ }^{1}$. Posteriormente as entrevistas foram transcritas pela pesquisadora. Os auxiliares foram treinados durante dois meses antes da coleta, e vários pré-testes foram realizados. Não houve intercorrências na coleta. A utilização do vídeo teve como objetivo conferir os registros nos protocolos. Os dados em relação ao processo de Tomada de Consciência foram obtidos através dos registros verbais gravados. Os nomes utilizados são fictícios.

Cada participante passou igualmente pelas mesmas etapas e adolescentes e idosos não se encontraram e não jogaram entre si. Nenhum deles tinha tido contato prévio com o jogo:

Etapa 1: adaptação. Jogar com a experimentadora três partidas. O objetivo era aprender as regras do jogo, até então desconhecido por todos. Ao final respondiam a um questionário para saber se haviam compreendido plenamente o jogo.

Etapa 2: jogar com o adversário três partidas. O objetivo era construir estratégias para o jogo.

Etapa 3: os dois auxiliares de pesquisa, de posse dos registros de uma das partidas realizadas entre os participantes, repetiam para cada um deles, individualmente, os lances de uma partida anterior. Era escolhida a partida com jogadas mais complexas. Utilizando o método clínico, a experimentadora entrevistava o participante enquanto ele assistia à repetição da partida que ele próprio havia jogado. Os auxiliares repetiam as jogadas lentamente, e interrompiam o jogo quando o participante desejava fazer

\footnotetext{
Flávio Martins de Souza Mendes e Mayra Amado Barcelos de Oliveira, alunos de graduação em Psicologia da Univix - Faculdade Brasileira.
} 
observações. Ele tinha liberdade para movimentar peças, testar possibilidades e jogadas no próprio jogo. Ao final de cada observação, retomava-se a partida original. O objetivo era analisar o processo de Tomada de Consciência.

Etapa 4: situações-problema: os participantes respondiam a situaçõesproblema previamente testadas, com o objetivo de identificar a plena compreensão das estratégias do jogo.

\section{Critérios de Análise dos Dados}

Para efeito de análise, foram propostos três níveis de Tomada de Consciência, com base no modelo piagetiano, no desempenho no jogo e nos relatos verbais dos participantes: Tomada de Consciência Periférica, Tomada de Consciência com Tendência à Centralidade e Conceituação Sobre a Ação.

De acordo com o relato verbal dos participantes e com o desempenho no jogo, foram estabelecidos sub-níveis, nomeados aqui de "A" e " $B$ ". Foram encontrados graus diferentes de Tomada de Consciência entre os participantes e num mesmo participante, em etapas diferentes da pesquisa. A elaboração de níveis, ou graus de Tomada de Consciência foi um procedimento utilizado nos estudos já mencionados (MORO, 2005; MORENO HERNÁNDEZ, 1998; MACEDO, 1994) e na pesquisa realizada por Ferreira e Lautert (2003). Apesar de observarem o processo de Tomada de Consciência a partir de objetivos diferentes dos utilizados nesta pesquisa, todos retratam uma evolução no processo, sempre caminhando do menos evoluído para o mais evoluído. Os níveis e sub-níveis serão descritos a seguir:

\subsection{Tomada de Consciência Periférica}

Refere-se exclusivamente à consciência do êxito ou fracasso, necessariamente sem observações sobre a participação ativa do próprio participante no resultado final da ação. Não envolve regulações. É o alcance ou não dos objetivos propostos. "Reação mais imediata e exterior do sujeito em face do objeto: utilizá-lo em conformidade com o objetivo e anotar o resultado obtido." (Piaget, 1977, p. 198). Neste caso, demonstrar uma Tomada de Consciência Periférica não significa que o participante não seja capaz de fazer uma Tomada de Consciência Central. Simplesmente não a expressou verbalmente naquele momento. 
Esta categoria foi dividida em dois sub-níveis:

\subsubsection{Sub-nível A}

Neste sub-nível, a análise dos participantes se refere apenas ao alcance ou não dos objetivos propostos. Não considera a participação dialética do adversário. É a simples constatação do resultado final da ação: êxito ou fracasso.

Exemplo: Tadeu (65 anos) “É. Eu perdi todas duas [partidas].”

\subsubsection{Sub-nível B}

Necessariamente, menciona o papel do adversário no êxito ou fracasso. Já começa a perceber uma relação de interdependência entre suas ações e as do adversário.

Exemplo: Geraldo (67 anos)"'[... ] agora, naquele segundo [jogo] eu cerquei ele. Ele deu um vacilo e aquele vacilo foi fatal para ele."

\subsection{Tomada de Consciência com Tendência à Centralidade}

O participante, neste caso, consegue expressar algumas razões do êxito ou fracasso. Envolve regulações. Processo que tem por objetivo de "[ ... ] alcançar o reconhecimento dos meios empregados, motivos de sua escolha ou de sua modificação durante a experiência [ . . . .." (Piaget, 1977, p. 198).

\subsubsection{Sub-nível A}

Os motivos de fracasso ou do êxito são analisados, considerando sempre uma relação dialética com o adversário. Neste nível, o jogador referese exclusivamente a uma ação específica, não generalizando, nem formulando uma estratégia geral para o jogo.

Exemplo: Experimentadora: "Qual foi o vacilo aqui?"

Geraldo (67 anos): "Dele. Uai. Ele colocou e fechou aqui, né? Eu estou aqui. Ele fechou, ó gastou todas as pedrinhas dele. Eu tenho quatro ainda. Para fechar ele de qualquer maneira. Agora não tem... onde ele correr aqui, eu chego aqui primeiro que ele. 1.2.3.4.5.6.7 e 1.2.3.4.5.6. olha..." 


\subsubsection{Sub-nível B}

Mantém as características do nível anterior, mas acrescenta a verbalização de uma estratégia específica para o jogo. Não menciona, ainda, uma estratégia geral para o jogo. Atribui seu êxito ou fracasso exclusivamente a uma estratégia que não necessariamente é responsável única ou direta para ganhar o jogo.

Exemplo: Tadeu (65 anos): “Ontem em casa, eu meditando. Eu falei... isso aqui, mas o importante aqui é conhecer a regra. Você sabe o que você pode e o que não pode. Você sabe o que você pode aprontar. Se não conhecer, fica meio receoso. Quando você vai perguntar, aí o adversário se alerta. Tem que saber a regra. Tem que ter conhecimento. Pra você não se confundir. Pensar que é uma coisa e é outra."

\subsubsection{Sub-nível C}

Mantém as características dos níveis anteriores, mas consegue verbalizar uma estratégia geral para o jogo como justificativa de seu êxito ou fracasso, demonstrando compreender de maneira mais aprofundada o sistema do jogo.

Exemplo: Geraldo (67 anos): “O que ele poderia ter feito... na saída ter ido direto pro centro, como eu fiz com o Tadeu, naquela jogada que eu ganhei o jogo... fui no centro e dali eu delineei onde eu queria ir. Eu usei as barreiras de acordo com as necessidades. Ele tem que gastar menos barreiras. É o principal. Não sei se você joga jogo da velha. Eu tinha um sistema que dava empate. Eu botava um $\mathrm{x}$ aqui, ele botava um zero aqui. Eu botava aqui, então, dava empate, empate. Mesma coisa aqui. Se ele souber usar no início, com inteligência. Se ele souber usar, ele ganha o jogo."

\subsection{Conceituação sobre a Ação}

Como descrito por Piaget (1977), conceituar sobre a ação implica no participante antecipar as conseqüências de uma jogada antes de agir, formulando uma teoria com possibilidades de êxito. Primeiro ele teoriza, para só depois testar se o que elaborou realmente leva ao êxito. É o nível mais evoluído de Tomada de Consciência. Não encontramos relatos verbais que se enquadrassem neste nível. 


\section{Resultados e Discussão}

Considerando todas as categorias de análise dos níveis de Tomada de Consciência acima descritos, os idosos relataram 16 episódios de Tomada de Consciência, e os adolescentes, seis. A motivação não parece ter sido uma variável que interferiu neste fato, porque ambas as duplas se mostraram muito motivadas, inclusive perguntando se haveria novos encontros. Não houve diferenças entre os participantes idosos e adolescentes quanto às estratégias utilizadas. Na dupla de adolescentes um participante se sobressaiu, e na dupla de idosos, também. Nenhum deles conseguiu alcançar, por exemplo, uma estratégia importante para ganhar o jogo, como barrar a si mesmo para controlar a ação do adversário. Durante as partidas, as duas duplas utilizaram estratégias tais como: colocar barreiras para impedir o adversário, economizar barreiras, avançar o peão em linha reta.

O tempo de reação dos idosos foi maior (partidas com tempo aproximado de 9 min.) do que o dos adolescentes (tempo aproximado de 3 min.). As diferença mais marcantes encontradas entre as duas duplas se refere à maneira como analisam seus êxitos e fracassos e como se relacionam com o adversário e com o próprio jogo. Por outro lado, os idosos, ao observarem os auxiliares de pesquisa, fizeram considerações sobre aspectos da vida cotidiana usando o jogo como metáfora, como no exemplo a seguir:

"Tem que saber usar as barreiras, gastar as barreiras, porque senão é fatal. Porque o peão é apenas um jogador. A barreira você tem que ter inteligência pra usar as barreiras. Temos que usar mais a cabeça. Tem que pensar em usar as barreiras. É a mesma coisa que você saber gastar o que você tem no bolso. Se não souber gastar você vai ficar endividado. As barreiras, pra mim, é a fortuna. Você tem que saber usar. Se você saber usar [sic], você tem $60,70 \%$ de possibilidade de ganhar o jogo, agora se você for gastando, aí o adversário... aí é moleza pra ele, ele ganha tranqüilamente." (Geraldo, 67 anos).

Este aspecto reflexivo, que compara situações de jogo a situações da vida, esteve presente durante os encontros com idosos, ao contrário dos adolescentes. Não estamos afirmando que os adolescentes não sejam capazes de fazê-lo. Apenas observamos que, espontaneamente, não foi uma prática observada entre os mais jovens.

O Sr. Geraldo apresentou um processo de Tomada de Consciência mais evoluído. O Sr. Tadeu, ao contrário, dos quatro participantes, foi o que 
apresentou processos menos evoluídos. Ainda assim a relação entre os dois jogadores idosos foi diferente dos dois jogadores adolescentes.

A descrição literal de uma seqüência de diálogos da dupla de adolescentes e da dupla de idosos pode exemplificar a diferença encontrada entre elas:

Seqüência de diálogo espontâneo dos jogadores idosos durante uma partida:

G: Gerado; T: Tadeu; P: pesquisadora

G: "Quando eu pus aquela peça eu sabia que eu ia perder porque eu trabalhava mais com as barreiras do que com o peão. A barreira é o principal."

T: "É."

G: "A barreira, se souber usar menos barreira, o peão é conseqüência."

T: "O principal é a primeira jogada."

P: "O principal é primeira jogada?"

T: "É a primeira jogada."

G: "Pra mim o principal é... é... o peão... é a barreira. Se você coordenar a barreira com o peão, entendeu? Você consegue ultrapassar, você consegue fazer chegar..."

T: "São 9 números?"

G: "São 10."

T: "Aqui. 1, 2, 3, 4, 5, 6, 7, 8, 9 [conta as casas]."

G: "Ah, eu pensei que era aqui [as barreiras]. Eh... bom... deixa para outro dia, agora."

T: "Cinco para cá e quatro para cá. Esse um é indivisível. Se a gente sai de lá, confrontando."

G: "Eu sei, tudo bem. Mas pra mim o principal é a barreira. Tanto é que quando eu vi essa jogada, contei as pedras, contei as vagas, eu sabia... eu sabia...você tinha quatro chances e eu eu tinha seis chances, logicamente você levava vantagem. E eu não tinha mais barreira nenhuma...acabou."

Este diálogo prossegue e eles vão espontaneamente começando o jogo várias vezes, sem terminá-lo, apenas para descobrir se seria melhor ser o primeiro a jogar. Eles descobrem que, ao contrário das aparências, neste jogo é melhor ser o segundo a começar.

O Sr. Tadeu considera que analisar o começo do jogo é suficiente para ganhá-lo, o que não é uma realidade. Entretanto, é uma estratégia 
importante, porque de fato o jogador que sai primeiro leva desvantagem, ao se confrontar com o adversário no meio do tabuleiro e permitir que este pule por cima, avançando uma casa a mais. O Sr. Geraldo, por sua vez, retrata uma estratégia realmente decisiva para ganhar o jogo. Em vários momentos diálogos assim aconteceram, sempre procurando entender o sistema do jogo.

Não parece correto pensar que a cooperação entre os idosos elimina o caráter de disputa. Alguns comportamentos apontam para a competição entre os idosos: relatos de que ficaram pensando em como melhorar o desempenho; sorrisos ao vencerem uma partida; comentários do tipo: "[ $\ldots$ ] tem o seguinte, eu não jogo para perder. "(Geraldo, 67 anos). É possível aventar a hipótese de que a maturidade pode ser responsável pela vontade de ganhar do adversário em condições de igualdade e de conhecimento do sistema do jogo. A cooperação, neste caso, seria importante porque ambos estavam aprendendo. Entretanto, isso não elimina a vontade de vencer.

Descrição das três partidas jogadas pela dupla de adolescentes:

Observe que não há diálogo entre os participantes:

L: Leandro; J: João; P: pesquisadora

Começa a partida. Antes de irem para o laboratório, onde foi realizada coleta, eles estavam jogando pingue-pongue. Demonstraram muita competitividade, comentando quem tinha ganhado esta e outras partidas. Durante o jogo na coleta, eles mantiveram o mesmo ritmo acelerado do jogo de pingue-pongue. Além disso, quando Leandro estava perdendo, pegava o peão com firmeza e chegava a fazer barulho no tabuleiro ao mudar o peão de casa.

J: "Ta aí."

L: “Aqui você não tem onde passar. Ah! É, voltou... droga!"

J: "Hum, hum... ri [ganhou]."

$2^{a}$ partida:

Não fizeram nenhum comentário no decorrer da partida. Leandro ganhou.

$\mathrm{J}$ : "Tinha como fazer alguma coisa?"

L: [Sorri].

$3^{\mathrm{a}}$ partida:

Silêncio absoluto. Do começo ao fim. João ganhou. 
É fundamental frisar que esta seqüência de diálogos demonstra apenas a diferença entre a disposição para conversar sobre o jogo entre os idosos e os adolescentes. A análise do processo de Tomada de Consciência, como já descrito, ocorre principalmente em um terceiro momento, onde cada participante analisa, individualmente, suas jogadas. Entretanto, como os idosos dialogaram mais sobre o jogo, tiveram oportunidade e tempo para repensar estratégias e entender o sistema do jogo.

Não foi objetivo deste trabalho classificar os participantes, mas descrever e analisar seus processos de Tomada de Consciência. Nenhum deles, nem idosos, nem adolescentes, chegou ao nível da conceituação sobre a ação, que é o nível mais elevado. Este foi um dos momentos em que a participação dos adolescentes auxiliou na análise. Como participantes de nenhuma faixa etária conseguiu chegar ao $3^{\circ}$ nível, outras hipóteses, além da idade, precisam ser aventadas. Somente investigações subseqüentes, inclusive utilizando este jogo, poderão esclarecer estes pontos.

A dupla de adolescentes, neste experimento, não verbalizou uma Tomada de Consciência que caracterizasse uma conceituação sobre a ação (Nível 3). Portanto, os idosos relataram uma quantidade maior de Tomada de Consciência, e um deles atingiu um nível maior que os outros três participantes. É sabido que um estudo de natureza qualitativa, com apenas quatro participantes, impede generalizações. Qualquer método escolhido numa investigação implica em vantagens e desvantagens. Ainda assim, é preciso informar que, neste experimento, o processo de Tomada de Consciência de um dos idosos (Geraldo, 67 anos) teve mais tendência à centralidade que os demais participantes, incluindo os adolescentes. Como se observa no recorte de diálogo citado anteriormente, ele demonstrou uma preocupação em entender o sistema do jogo, e relatou, em várias oportunidades, estratégias fundamentais para se ganhar o jogo.

\section{Considerações Finais}

Um ponto que parece relevante destacar neste estudo é que a análise do processo de Tomada de Consciência pode significar um instrumento válido para intervenções em indivíduos idosos. Ao lado dos aspectos físicos, emocionais e sexuais, a cognição precisa ser uma característica também trabalhada e desenvolvida. A noção de desenvolvimento que este estudo adota não admite interrupções justificadas exclusivamente pela faixa etária. 
Ao investigar o processo de Tomada de Consciência, parece possível estabelecer uma hipótese de que o próprio fato de ser estimulado a pensar sobre êxitos e fracassos altera o conhecimento sobre o objeto, sobre o comportamento e sobre o desempenho no jogo. Este parece ser um caminho viável para trabalhar cognição com idosos.

O importante a ser ressaltado não é a comparação dicotômica juventude-velhice. A comparação serve apenas ao objetivo de reconhecer características próprias de uma faixa etária. $\mathrm{O}$ fato é que um dos idosos foi capaz, neste experimento, de demonstrar um funcionamento cognitivo mais evoluído que os demais participantes, incluindo os adolescentes. Apesar de não ser possível generalizar os dados obtidos neste estudo, os resultados aqui encontrados possibilitam questionar a generalização de que todos os idosos, em situações novas, que envolvam resoluções de problemas, demonstram declínio cognitivo. Reafirmamos os dados encontrados na literatura científica, que indica que o processo de envelhecimento não é igual para todos, e que aspectos genéticos e sociais podem influenciar no declínio cognitivo.

\title{
THE COGNITIVE FUNCTIONING OF ELDERS AND TEENAGERS IN A CONTEXT OF GAMES OF RULES
}

\begin{abstract}
The studies on cognition, in many cases, refer mainly to memory and attention. This research used the model proposed by Piaget (1977) denominated Grasp of Consciousness. This part of the theory aims to analyze aspects related to the process of cognitive functioning of elderly people. The objective was to characterize the process of Grasp of Consciousness of elders and teenagers, in a context of games of rules. The participants lived in middle class neighborhoods, and had attended public schools. The adolescents were on the first grade of High School while the elders had had already concluded it. The choice of teenagers is due to the fact that for Piaget, the apex of cognitive development is the formal operational stage reached starting from adolescence. However, the object of this research was the cognitive functioning of elders. Teenagers were included to help define the characteristics found, so to provide better understanding of the aging process in simple, controlled
\end{abstract}


situations. This is a qualitative exploratory study, based on the Piagetian clinical method. This research was carried out with two teenagers and two young elders. The instrument used for the data gathering was a game of rules named Quoridor. The results indicate that, in many aspects, the process of Grasp of Consciousness of the elders and teenagers in this research was similar. However, qualitative differences were observed throughout the data analysis, and they may indicate a direction for the development of intervention in the cognitive aspects of elders.

Keywords: Elderly. Piaget. Games. Grasp of Consciousness. Cognition.

\section{REFERÊNCIAS}

ARGIMON, Irani I. de Lima; STEIN, Lilian Milnitsky. Habilidades Cognitivas em Indivíduos muito Idosos: um estudo longitudinal. Cadernos de Saúde Pública, Rio de Janeiro, v. 21, n. 1, 2005. Disponível em: $<$ http:// www.scielo.br/scielo.php?script=sci_arttext\&pid=S 0102 311X2005000100008\&lng=pt\&nrm=iso > . Acesso em: 13 mar. 2006.

ANSTEY, Kaarin J.; HOFER, Scott M.; LUSZCZ, Mary A. Cross-sectional and Longitudinal Patterns of Dedifferentiation in Late-Life Cognitive and Sensory Function: the effects of age, ability, attrition and occasion of measurement. Journal of Experimental Psychology: General, Washington, v. 132, n. 3, p. 470-487, 2003. Disponível em: <http://www.apa.org/journals/ releases/xge1323470.pdf>. Acesso em: 20 jan. 2006.

BRASIL. Ministério da Saúde. Redes Estaduais de Atenção à Saúde do Idoso. Brasília, DF: Ministério da Saúde, 2001, Disponível em: $<$ http:// www.dtr2001.saude.gov.br/bvs/publicacoes/redes_estaduais.pdf $>$. Acesso em: 19 jan. 2006.

DENISE, Head et al. Age-Related Differences in the Course of Cognitive Skill Acquisition: the role of regional cortical shrinkage and cognitive resources. Psychology and Aging, Washington, v. 17, n. 1, p. 72-84, 2002. Disponível em: $<$ http://gateway.ut.ovid.com/gw1/ovidweb.cgi $>$. Acesso em: 18 jan. 2006. 
DÍAZ, Basilia Estela; MARTINEZ LOZANO, Ana Josefa; NUNEZ RODRIGUEZ, Vidalina Características biopsicosociales en una población anciana. Revista Cubana de Enfermería, Habana, v. 19, n. 3, 2003. Disponível em: $<$ http://scielo.sld.cu/scielo.php?script=sci_pdf\&pid=S086403192003000300007\&lng=es\&nrm=iso\&tlng=es $>$. Acesso em: 03 mar. 2006.

BEE, Helen. Mudanças Físicas e Cognitivas na Velhice. In: . OCiclo Vital. Porto Alegre: Artes médicas, 1997. P. 515-548.

FERREIRA, Sandra Patrícia Ataíde; LAUTERT, Síntria Labres. A Tomada de Consciência Analisada a partir do Conceito de Divisão: um estudo de caso. Psicologia: Reflexão e Crítica, Porto Alegre, v. 16, n. 3, 2003, p. 547-554. Disponível em: $<$ http://www.scielo.br/scielo.php?pid=S0102$79722003000300013 \&$ script $=$ sci_arttext\&tlng=pt $>$. Acesso em: 18 jan. 2006.

MORENO HERNÁNDEZ, Amparo. La consciencia como conceptualizacion: Piaget y la Escuela de Ginebra. In: Perspectivas psicológicas sobre la consciência: su desarrollo en relación con la acción. Madrid: Ediciones de la Universidad Autónoma de Madrid, 1988. P. 53-69.

INSTITUTO BRASILEIRO DE GEOGRAFIA E ESTATÍSTICA. Dia do Idoso. [Brasília, DF: IBGE, 200-?] Disponível em: < http://www.ibge.gov.br/ ibgeteen/datas/idoso/idoso_no_mundo.html >. Acesso em: 19 jan. 2006.

IL FOGLIACCIO DEGLI ASTRATTI, Torino: [s.n.], n. 25, 14 Novembre 2004. Disponível em: $<$ http://www.pergioco.net/Giochi/FogliaccioAstratti/ FdA\%2025/FdA\%2025.html >. Acesso em: 27 jan. 2006.

LÖVDÉN, Martin; GHISLETTA, Paolo; LINDENBERGER, Ulman. Social Participation Attenuates Decline in Perceptual Speed in Old and Very Old Age. Psychology and Aging, Arlington, v. 20, n. 3, p. 423-434, 2005. Disponível em: $<$ http://gateway.ut.ovid.com/gw1/ovidweb.cgi $>$. Acesso em: 18 jan. 2006. 
MACEDO, Lino. Inconsciente e Recalcamento Cognitivo. In:

Ensaios Construtivistas. São Paulo: Casa do Psicólogo, 1994. P. 163170.

MACEDO, Lino; PETTY, Ana Lúcia Sícoli; PASSOS, Norimar Christe. Introdução. In: . Aprender com Jogos e Situações-problema. Porto Alegre: Artmed, 2000. P. 11-23.

MELTZOFF, Julian. Research Questions and Hypotheses. In:

Critical Thinking About Research: Psychology and related fields. Washington: American Psychological Association, 2001. P. 13-21.

MORO, Maria Lucia Faria. Estruturas Multiplicativas e Tomada de Consciência: repartir para dividir. Psicologia: Teoria e Pesquisa, Brasília, v. 21, n. 2, 2005. Disponível em: <http://www.scielo.br/ scielo.php?script $=$ sci_arttext\&pid=S0101-37722005000200012\&LNG $=$ en \&nvm=iso $>$. Acesso em: 25 jan. 2006.

NERI, Anita Liberalesso (Org.). Desenvolvimento e Envelhecimento: perspectivas biológicas, psicológicas e sociológicas. Campinas: Papirus, 2001.

ORTEGA, Antonio Carlos et al. Aspectos Psicogenéticos do Pensamento Dialético no Jogo Mastergoal. In: NOVO, Helerina Aparecida; MENANDRO, Maria Cristina Smith (Org.). Olhares Diversos: estudando o desenvolvimento humano. Vitória: UFES, 2000. P. 73-90.

PAPALIA, Diane E.; OLDS, Sally Wendkos. Desenvolvimento Físico e Cognitivo na Terceira Idade. In: Desenvolvimento Humano. 7. ed. Porto Alegre: Artmed, 2000. P. $\overline{491-519}$.

PIAGET, Jean. Os Problemas e os Métodos. In: do Mundo na Criança. Rio de Janeiro: Record, [19-]. P. 5-28.

PIAGET, Jean. A Equilibração das Estruturas Cognitivas: problema central do desenvolvimento. Rio de Janeiro: Zahar, 1976. 
PIAGET, Jean. A Tomada de Consciência. São Paulo: Melhoramentos, 1977.

PIAGET, Jean. Fazer e Compreender. São Paulo: Ed. da Universidade Federal de São Paulo, 1978.

PIC88865.JPG. 2005. Quoridor. Altura: 755 pixels. Largura: 565 pixels. 381.629 bytes. Formato JPEG. Disponível em: $<$ http://s3.amazonaws.com/ boardgamegeek/images/pic88865.jpg>. Acesso em: 20 mar. 2006

ROSSETTI, Claudia Broetto; SOUZA, Maria Thereza Costa Coelho de. Jogos de Regras e Cognição: uma revisão da produção de três grupos de pesquisa brasileiros. In: QUEIROZ, Sávio Silveira de; ORTEGA, Antonio Carlos; ENUMO, Sônia Regina Fiorim. (Org.). Desenvolvimento e Aprendizagem Humana: temas contemporâneos. Vitória: GM, 2005. P. $27-$ 44.

SCHAIE, K. Warner. Intellectual Development in Adulthood. In: BIRREN, James E.; SCHAIE, K.Warner. (Ed.). Handbook of the Psychology of Aging. 4. ed. San Diego: Academic Press, 1996. P. 266-286. Disponível em: $<$ http://geron.psu.edu/sls/publications/BookChJouArt.htm $>$. Acesso em: 18 jan. 2006.

SCHAIE, K. Warner. Cognitive Aging. In: PEW, Richard W.; VAN HEMEL, Susan B. (Ed.). Technology for Adaptive Aging. Washington: National Academy Press, 2004. P. 41-63. Disponível em: $<$ http://geron.psu.edu/sls/ publications/BookChJouArt.htm>. Acesso em: 18 jan. 2006.

SCHAIE, K. Warner. What can we Learn from Longitudinal Studies of Adult Intellectual Development. Research in Human Development, Medford, v. 2, n. 3, p. 133-158, 2005. Disponível em: <http://geron.psu.edu/sls/ publications/What $\% 20 \mathrm{can} \% 20 \mathrm{we} \% 20$ learn $\% 20$ from $\% 20$ long.pdf $>$. Acesso em: 18 jan. 2006.

STEVENS, Fred C. J. et al. How Ageing and Social Factors Affect Memory. Age and Ageing, London, v. 28, n. 4, p. 379-384, 1999. Disponível em: 
$<$ http://ageing.oxfordjournals.org/cgi/reprint/28/4/379>. Acesso em: 21 jan. 2006.

WEST, Robin L.; BAGMWELL, Dana K.; DARK-FREUDEMAN, Alissa. Memory and Goal Setting: the response of older and yonger adults to positive and objective feedback. Psychology and Aging, Washington, v. 20, n. 2, p. 195-201, 2005. Disponível em: <http://gateway.ut.ovid.com/gw1/ ovidweb.cgi>. Acesso em: 18 jan. 2006. 